\title{
Ablación septal alcohólica: presentación de un caso y revisión de la técnica
}

\section{Alcoholic septal ablation: case presentation and review of its technique}

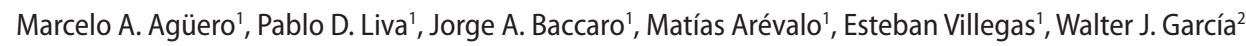

\section{RESUMEN}

La ablación septal alcohólica es una técnica de reducción septal mínimamente invasiva para pacientes con miocardiopatía hipertrófica obstructiva que persisten sintomáticos a pesar del tratamiento farmacológico. Presentamos un caso clínico de ablación septal alcohólica y una descripción de la técnica para un procedimiento efectivo y seguro.

Palabras claves: miocardiopatía hipertrófica obstructiva, terapia de reducción septal, ablación septal alcohólica.

\section{ABSTRACT}

Alcoholic septal ablation is a minimally invasive septal reduction technique for patients with hypertrophic obstructive cardiomyopathy who remain symptomatic on maximally tolerated medical therapy. We report a case of alcoholic septal ablation and its technique.

Key words: obstructive hypertrophic cardiomyopathy, septal reduction therapy, alcohol septal ablation.

Revista Argentina de Cardioangiología Intervencionista 2019;10(4):0184-0186. https://doi.org/10.30567/RACI/201904/0184-0186

\section{INTRODUCCIÓN}

La miocardiopatía hipertrófica (MCPH) es una patología heterogénea que se define ante la presencia de hipertrofia ventricular asimétrica o desproporcionada, o no explicada por condiciones de carga ${ }^{1}$.

Es una patología de origen genético, producida por mutaciones en genes que codifican proteínas sarcoméricas. Su prevalencia es 1:500 y es hereditaria en alrededor del $50 \%$ de los pacientes ${ }^{2}$. Su espectro clínico es muy diverso. En algunos casos es asintomática y se detecta incidentalmente. En otras ocasiones se manifiesta con disnea, angor o síncope, pudiendo incluso debutar con muerte súbita ${ }^{2}$.

El desarrollo de gradiente intraventricular $>30 \mathrm{mmHg}$ define a la MCPH obstructiva. Esta obstrucción puede localizarse a nivel medioventricular o en el tracto de salida del VI. En el 30\% de los pacientes la MCPH es obstructiva en reposo y en otro $30 \%$ se desarrolla obstrucción con maniobras provocadoras (Valsalva y ejercicio) ${ }^{2}$.

La obstrucción dinámica en el tracto de salida (TSVI) es dependiente de condiciones de carga y de contractilidad, y producida por el movimiento anormal sistólico (MAS) de la valva anterior mitral. El MAS se produce por efecto Venturi sumado a anomalías estructurales y funcionales del aparato subvalvular mitral.

El tratamiento farmacológico es útil para aliviar los síntomas. Los pacientes con disnea/insuficiencia cardíaca son habitualmente manejados con drogas que disminuyen el inotropismo (betabloqueantes y bloqueantes cálcicos) y que alivian la congestión (diuréticos). Los pacientes que a pesar del tratamiento farmacológico persisten con síntomas severos

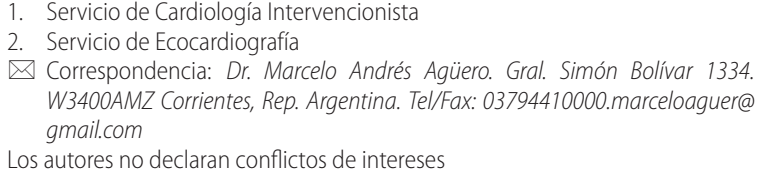

$\triangle$ Correspondencia: Dr. Marcelo Andrés Agüero. Gral. Simón Bolivar 1334. W3400AMZ Corrientes, Rep. Argentina.Tel/Fax:03794410000.marceloaguer@ gmail.com

Los autores no declaran conflictos de intereses

Recibido: 03/06/2019|Aceptado:04/10/2019 (presíncope o síncope recurrente de esfuerzo o disnea CF III-IV) deben ser considerados para terapias de reducción septal, entre las que figuran la miomectomía quirúrgica y la ablación septal alcohólica (ASA) ${ }^{3}$.

Presentamos un caso clínico de una paciente con $\mathrm{MCPH}$ obstructiva sintomática refractaria al tratamiento médico sometida a ASA, con descripción de la técnica.

\section{CASO CLÍNICO}

Paciente de 62 años, hipertensa estadio I, diabética tipo 2, extabaquista, sintomática por disnea CF II habitual que progresa en los últimos meses a CF III, por lo que consulta. En el ECG se constata sobrecarga de aurícula y ventrículo izquierdos. En eco-Doppler: función sistólica del VI conserva$\mathrm{da}$, septum $18 \mathrm{~mm}$, pared posterior $13 \mathrm{~mm}$, insuficiencia mitral moderada por MAS, gradiente en TSVI de $27 \mathrm{mmHg}$ en reposo que se eleva a $89 \mathrm{mmHg}$ con Valsalva. Continúa sintomática a pesar del tratamiento con bisoprolol, diltiazem y furosemida.

Es evaluada por Rx de tórax y espirometría, resultando ambos estudios normales. Finalmente, y con el fin de descartar otras causas de disnea, se realizó test cardiopulmonar, siendo el test detenido precozmente por disnea, con discreta caída del consumo de $\mathrm{O}_{2}$ (83\% del valor predicho) y pulso de $\mathrm{O}_{2}$ con meseta en el pico de ejercicio, hallazgos sugestivos de disnea de origen cardíaco y comportamiento característico de la miocardiopatía hipertrófica.

Se realiza coronariografía descartándose la presencia de enfermedad coronaria obstructiva.

Ante la persistencia de síntomas y habiendo descartado otras causas de disnea se propone la ASA.

\section{Procedimiento}

Se procede a la anestesia general, intubación orotraqueal y se coloca sonda de ETE para guiar el procedimiento. Se constata en la evaluación basal por ETE la presencia de IM moderada por MAS y desarrollo de gradiente severo en el TSVI (velocidad pico $5,1 \mathrm{~m} / \mathrm{s}$, gradiente $104 \mathrm{mmHg}$ ) (Figura 1). 


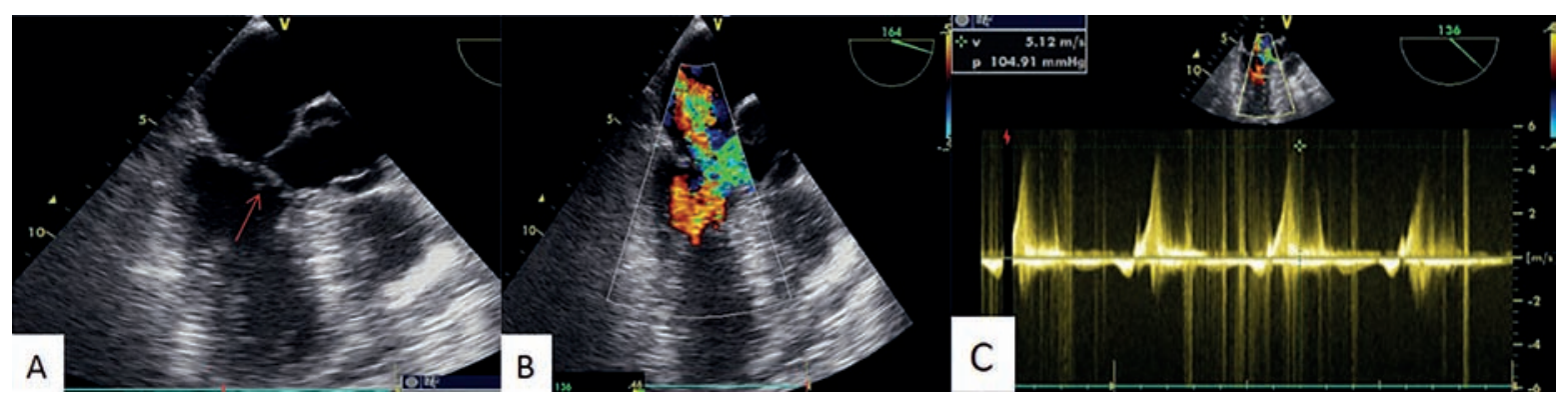

Figura 1. ETE basal. A ETE: vista LVOT. Movimiento anterior sistólico (MAS) de valva anterior mitral (flecha). B ETE: vista LVOT. Flujo turbulento en TSVI e Insuficiencia mitral. CETE: velocidad y gradiente pico con doppler continuo.
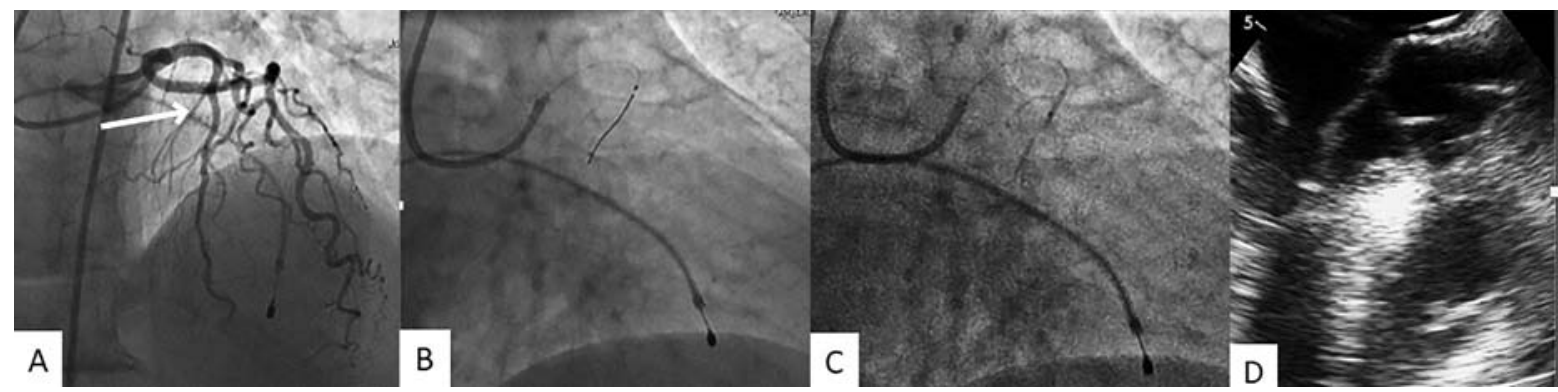

Figura 2. A Coronariografía: identificación del primer tramo septal (flecha). B Balón "over the fire wire" sobre cuerda HTF Il en primer tramo septal. C Inyección de contraste a través de la luz del balón. D Hiperecogenicidad en el septum basal.

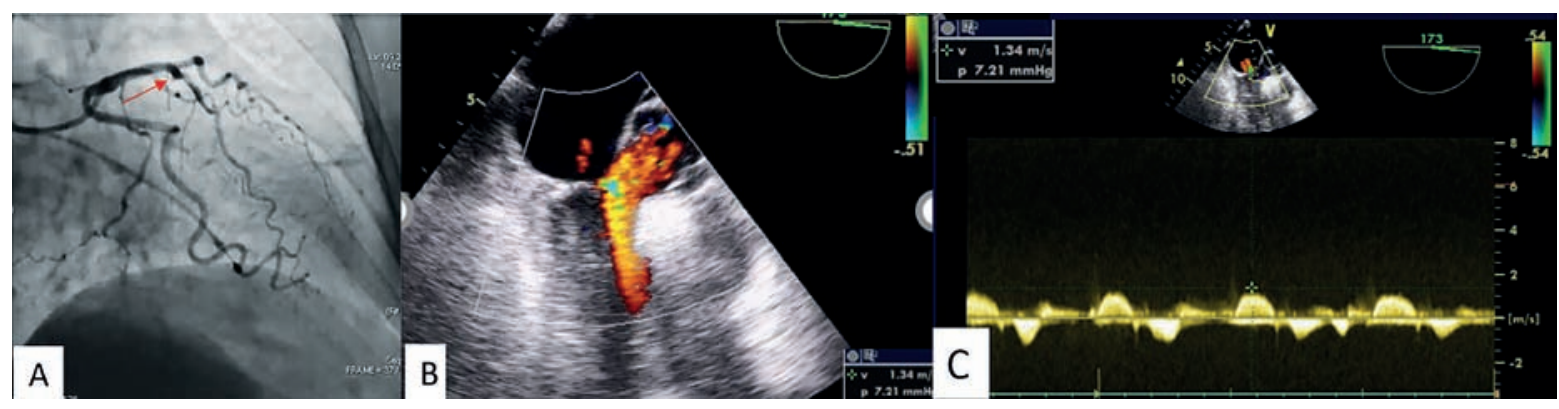

Figura 3. A Coronariografía post ASA: ausencia de flujo en el primer ramo septal (flecha). B ETE / Doppler color. Reducción de la IM. C ETE / Doppler continuo. Reducción de la velocidad en TSVI a $1.3 \mathrm{~m} / \mathrm{seg}$ y gradiente pico a $7 \mathrm{~mm} \mathrm{Hg}$.

Se punza vena femoral derecha y se coloca introductor 6 Fr a través del cual se coloca marcapasos transitorio.

Se punza arteria femoral derecha y se coloca introductor 6 Fr. Se administran $70 \mathrm{UI} / \mathrm{kg}$ de heparina $\mathrm{Na}$. Se lleva catéter guía JL 3,5 6 Fr y se realiza angiografía basal. Se identifica como vaso target un primer ramo septal de $1,5 \mathrm{~mm}$ de diámetro. Se lleva cuerda HTF 0,014" a dicho ramo y sobre la misma se avanza balón over the wire 1,5-12 $\mathrm{mm}$ el cual se insufla a 8 atm en el tercio proximal del vaso target. Se realiza inyección de contraste desde el catéter guía constatándose la ausencia de flujo hacia el vaso septal. Se retira la cuerda y a través de la luz del catéter balón se inyectan $2 \mathrm{ml}$ de contraste angiográfico con dos objetivos:

1) descartar reflujo hacia descendente anterior o apertura de colaterales a partir del ramo septal.

2) comprobar por ETE aumento de la refringencia a nivel del septum basal, en proximidad con la zona de aceleración de la velocidad de flujo (Figura 2).

Posteriormente se inyecta alcohol absoluto en dosis de 0,1 $\mathrm{ml} / \mathrm{mm}$ de espesor septal $(1,8 \mathrm{ml}$ en el caso de nuestra paciente) a través de la luz central del balón durante 3 a 5 minutos, seguido de insuflación prolongada del mismo (otros 3 a 5 minutos). Durante la instilación del alcohol se continúa monitoreando por ETE la ausencia de hiperecogenicidad en zonas remotas y la evolución del gradiente.

Finalizada la inyección de alcohol se retira cuerda y catéter balón y se realiza angiografía de control en la que se constata la ausencia de flujo en el vaso target y el flujo conservado en el resto del árbol coronario. En el ETE se constata reducción del gradiente máximo a $7 \mathrm{mmHg}$ y de la velocidad pico a $1,34 \mathrm{~m} / \mathrm{s}$, así como una reducción de la Insuficiencia mitral por Doppler color (Figura 3).

Finaliza el procedimiento sin complicaciones. La paciente es extubada en la sala de Hemodinamia.

\section{Evolución intrahospitalaria:}

Se constata en el laboratorio elevación de troponina (valor pico $932 \mathrm{ng} / \mathrm{ml}$ ) a las $6 \mathrm{hs}$ del procedimiento.

La paciente evoluciona estable clínicamente durante su internación, siendo dada de alta al 4to. día luego de la intervención.

\section{Evolución luego del alta}

Evoluciona luego con mejoría significativa de los síntomas (disnea CF I-II). A los 6 meses de seguimiento se realiza eco-Doppler de control persistiendo con una reducción significativa y sostenida del gradiente en el TSVI (velocidad pico 2,6 m/s, gradiente máximo $27 \mathrm{mmHg}$ ) (Figura 4).

\section{DISCUSIÓN}

La ablación septal alcohólica fue descripta por primera vez 


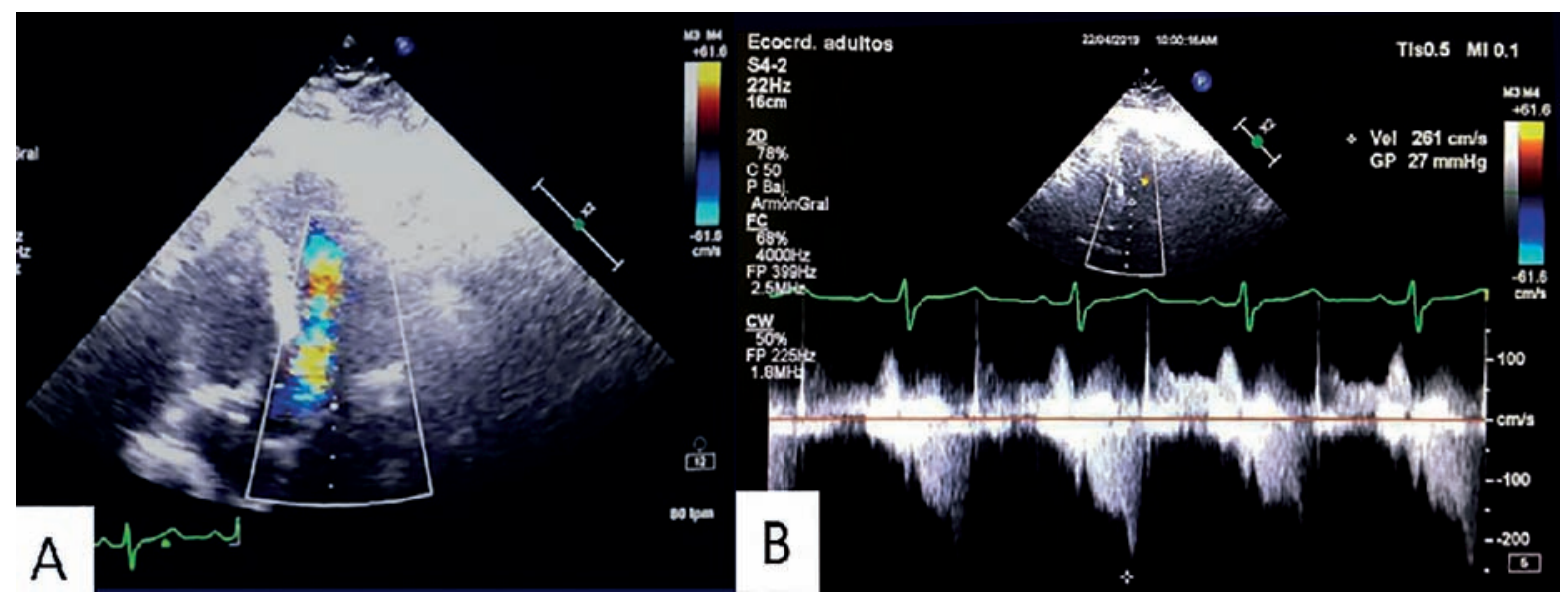

Figura 4. A ECO - Doppler color: leve turbulencia en TSVI. B ECO - Doppler continuo: velocidad pico $2.6 \mathrm{~m} / \mathrm{seg}$ y grad máximo $27 \mathrm{mmHg}$.

por Berghoffer en 1989. Se trata de una terapia de reducción septal efectiva y mínimamente invasiva para pacientes con MCPH obstructiva sintomática y refractaria al tratamiento farmacológico ${ }^{4}$. Su mayor utilidad se comprueba en pacientes con gradientes $>50 \mathrm{mmHg}$ en reposo o desencadenado por Valsalva o ejercicio ${ }^{2,3}$.

El riesgo de CIV posembolización disminuye con espesores septales superiores a $17 \mathrm{~mm}$ y su utilidad es dudosa en hipertrofias masivas ( $>25 \mathrm{~mm}$ de espesor septal).

La evaluación previa debe ser exhaustiva debiendo extremarse los medios para descartar patologías asociadas que puedan ser responsables de los síntomas.

Los estudios por imágenes como el eco-Doppler, ecotransesofágico y resonancia magnética (RNM) cardíaca son indispensables para el diagnóstico estructural y funcional como para detectar anomalías del aparato subvalvular mitral que pueden asociarse y modificar la indicación de la terapia de reducción septal hacia la miomectomía quirúrgica.

La coronariografía previa es útil tanto para descartar la enfermedad coronaria asociada como para identificar el vaso target para la instilación de alcohol. El vaso target habitual es el ler ramo septal. En un $10-15 \%$ de los casos no se identifica un vaso apropiado y en raras ocasiones el vaso target puede irrigar además músculos papilares, pared libre del VD o del VI, haciéndolo no adecuado para esta terapia ${ }^{3,5}$.

El éxito técnico se define ante la reducción del gradiente $>50 \%$ del basal, lo que se asocia a una mejoría clínica significa- tiva. Se ha reportado que el $90 \%$ de los pacientes tratados exitosamente resuelven o mejoran sus síntomas al año de seguimiento (CF I o II) y que la tasa de reintervención ronda el 7\%. No existen datos acerca de la utilidad pronóstica de la terapia. Dentro de las complicaciones del procedimiento, cabe mencionar la muerte (1\%), infarto en zonas remotas (cara anterior, músculos papilares, VD), la comunicación interventricular, las arritmias ventriculares y trastornos de conducción.

Para disminuir la probabilidad de complicaciones es importante la estrecha observación de los detalles técnicos descriptos y evitar instilar más de $2 \mathrm{ml}$ de alcohol en una sesión ${ }^{3}$.

No existen datos acerca de la seguridad a largo plazo de esta técnica, por lo que no debería utilizarse en niños o adultos jóvenes. (3)

\section{CONCLUSIONES}

La ablación septal alcohólica es una terapia mínimamente invasiva, efectiva y segura para pacientes con miocardiopatía hipertrófica sintomática a pesar del tratamiento farmacológico.

Una exhaustiva evaluación previa que permita seleccionar a los pacientes adecuados es mandatoria.

El cuidado meticuloso de la técnica de embolización permite llevar a cabo un procedimiento efectivo y minimizar el riesgo de complicaciones.

\section{BIBLIOGRAFÍA:}

1. Elliot PM, Zamorano JL, Anastasakis A, et al. Gardin JM, Skelton TN, et al. The task force for the diagnosis and management of hypertrophic cardiomyopathy of the ESC. Eur Heart J;35:2733-79.

2. Maron BJ. Clinical course and management of Hypertrophic Cardiomyopathy. N Engl J Med 2018;379:655-68.

3. Mestres CA, Bartel T, Sorgente A, et al. Hypertrophic obstructive cardiomyopathy: what, when, why, for whom? Eur J Cardiothorac Surg 2018;53:700-7.
4. Holmes DR, Valeti US, Nishimura RA. Alcohol septal ablation for hypertrophic cardiomypahty. Indications and technique. Catheter Cardiovasc Interv. 2005; 66: 375-89.

5. Alkhouli M, Sajjad W, Lee J, et al. Prevalence of non-left anterior descending septal perforator culprit in patients with hypertrophic cardiomypahty undergoing alcoholic septal ablation. Am J Cardiol. 2016; 117: $1655-60$ 